\title{
TERAPÊUTICAS COMPLEMENTARES E INTEGRATIVAS COMO OPÇÃO PARA REDUÇÃO DOS ESTRESSORES EM TRANSPORTE AEROMÉDICO PEDIÁTRICO
}

Michelle TAVERNA ${ }^{1}$, Mônica Beatriz Ortolan LIBARDI ${ }^{2}$, Selma de Almeida PINTO³, Guilherme Roberto ZAMMAR ${ }^{4}$

\section{RESUMO}

As aplicações de terapêuticas complementares e integrativas vêm ganhando relevância em Unidades de Terapia Intensiva (UTIs) neonatais e pediátricas em todo país. Considerando as acentuadas evidências no emprego prático em situações tais como: redução da dor, diminuição da ansiedade e melhor adesão ao tratamento (principalmente em pacientes críticos) percebemos que esta modalidade poderia ser aproveitada de forma significativa em voos aeromédicos. Este trabalho se baseou na investigação de literaturas que caracterizassem cientificamente os fundamentos das terapêuticas complementares e integrativas, bem como pela junção de artigos que revelassem a utilização prática destas em pacientes pediátricos. A principal fonte de busca foi nas bases de dados indexadas na Biblioteca Virtual em Saúde (BVS) e Scientific Eletronic Library Online (SciELO). A pesquisa revelou que muitos recursos são utilizados como alternativas para humanizar os ambientes frios e técnicos dos leitos hospitalares das UTI's como a plotagem ou projeção de imagens lúdicas, a musicoterapia, o pote da calma, brinquedo terapêutico e a cromoterapia. Este trabalho serviu como base para próxima fase da pesquisa que se ampliará com emprego das técnicas citadas acima em voos aeromédicos pediátricos da Helisul.

Palavras-chave: transporte aeromédico pediátrico, terapêuticas complementares e integrativas.

\section{INTRODUÇÃO}

A recuperação de paciente crítico requer a junção de equipamentos de alta tecnologia e recursos humanos especializados. Os conceitos bio-psico-socio-espiritual nos ambientes como Unidades de Terapia Intensiva (UTI's) são vistos como mais agressivos por serem mais invasivos e traumatizantes, o que gera uma percepção do atendimento, quase sempre, como desumanizada. Isso leva à um desafio a mais aos profissionais de saúde que trabalham nestes serviços, pois precisam integrar à sua assistência altamente especializada o cuidado sensível, personalizado e humanizado (ALMEIDA, 2012).

Com a utilização das tecnologias o cuidado holístico ao paciente se torna cada vez mais afastado da prática médica. (VILA; ROSSI, 2002).

1.Enfermeira de Voo Helisul. $1^{\circ}$ Ten da FAB, Presidente ABRAERO. Coordenadora do Dep. de Neurociência da ABRAERO. Curitiba, Paraná, Brasil. michelletaverna@hotmail.com

2. Enfermeira de Voo SAMU DF, Diretora ABRAERO, Coordenadora do Dep. Pediatria da ABRAERO. Brasília DF, Brasil. monicab.libardi@gmail.com

3. Enfermeira de Voo da Unimed Aeromédica, Belo Horizonte, Minas Gerais, Brasil. selmaapinto@gmail.com

4. Médico de voo Helisul, Curitiba, Paraná, Brasil. gzammar@gmail.com 
A aplicação de terapêuticas complementares e integrativas em pacientes internados nas UTI's retomam essa visão holística, conseguem quebrar as rotinas frias e impessoais desses ambientes, trazendo momentos de alegria, descontração e conforto espiritual, bem como são capazes de reduzir a tristeza, o estresse e a dor (SILVA et al., 2015).

A maioria dos pacientes pediátricos ao se depararem com o cenário lúdico, em sua maioria, evoluem com comportamentos verbais e não verbais surpreendentes. Realizam intervenções nos brinquedos, reproduzem o que Ihes foi ensinado e associam a semelhança deles com a realidade vivenciada no hospital. Após a sessão do brinquedo terapêutico (BT), aceitam melhor o cuidado dos profissionais, estabelecem interação com a equipe e propiciam vínculo/ confiança. Não raro, ao final da sessão do BT desejam permanecer com o brinquedo visto a satisfação e prazer vivenciados (FONTES, 2017).

A pedagogia Montessoriana traz a projeção lúdica do brincar como fator indispensável na pediatria. Cada brinquedo e brincadeira criados em seu método tem uma função para auxiliar o desenvolvimento da criança de uma forma lúdica.

Dentro desta proposta encontramos o pote da calma que é uma ferramenta simples que serve para acalmar a criança em momentos de choro, de estresse ou de muita agitação. Consiste em um pote ou garrafa transparente, com líquido colorido e glitter dentro, com bons resultados em salas de vacinação, em crianças com autismo e com Síndrome de Down por exemplo (FARIA; et al., 2012; ARAÚJO; et al. 2018).

Há muitas semelhanças entre as UTIs, os aviões e helicópteros utilizados para o transporte de pacientes críticos, entretanto, no voo há o acréscimo dos estressores pertinentes ao ambiente hipobárico como: variações na pressão, temperatura, vibração, ruídos, luminosidade, acelerações entre outros (SUEOKA, 2021).

Para ALMEIDA (2012), o relaxamento, integração entre o paciente e a equipe multiprofissional são alguns dos benefícios na utilização das terapias complementares e integrativas. Caberá a equipe de voo, determinar o interesse do paciente pela melhor alternativa para a promoção do conforto e bem-estar do paciente pediátrico ou mesmo para a descontração, o passatempo e/ou entretenimento, com foco na personalização e humanização do transporte aeromédico pediátrico. 


\section{CONAER \\ CONGRESSO AEROMÉDICO BRASILEIRO}

\section{METODOLOGIA}

Este trabalho se trata de uma pesquisa com levantamento de artigos cujo objetivo foi caracterizar a produção científica acerca dos fundamentos e a aplicação das terapias complementares e integrativas em pacientes pediátricos. A principal fonte de busca foi nas bases de dados indexadas na Biblioteca Virtual em Saúde (BVS) e Scientific Eletronic Library Online (SciELO). Com os seguintes descritores: UTI pediátrica e terapias integrativas. Sendo otimizado o período de produções de 2010 a 2021.

\section{RESULTADOS E DISCUSSÕES}

A terapêutica complementar e integrativa é definida como "um grupo de diversos sistemas, práticas e produtos médicos e de saúde que geralmente não são considerados parte da medicina convencional" (KIM; et al., 2016).

A literatura pesquisada inclui inúmeras práticas, dentre elas citamos algumas: massagem; musico terapêutica; exercícios de respiração profunda; cromoterapia; plotagem e projeção de imagens; meditação; relaxamento; acupuntura; ayurveda; biofeedback; terapia de cura energética; hipnose; técnicas mentais-corporais asiáticas (ioga, tai chi e / ou qigong); Hierbero; Yerbera; Shaman; brinquedo terapêutico; pote da calma etc. Além disso, vitaminas e minerais são usados rotineiramente para cuidados preventivos em pediatria.

Todas as terapêuticas apresentam um foco em comum: proporcionar um cuidado em saúde integral e humanizado, visto que considera o indivíduo em suas particularidades e emoções. Percebemos em algumas práticas complementares e integrativas a possibilidade de obtermos bons resultados na redução dos estressores de voo como forças acelerativas, hipóxia, variações de pressão e temperatura, aos quais são submetidos os pacientes pediátricos principalmente em longas transferências pelo modal aéreo. Dentre elas destacamos o pote da calma, a projeção de imagens, a plotagem lúdica e música terapêutica, ilustradas nas imagens abaixo:
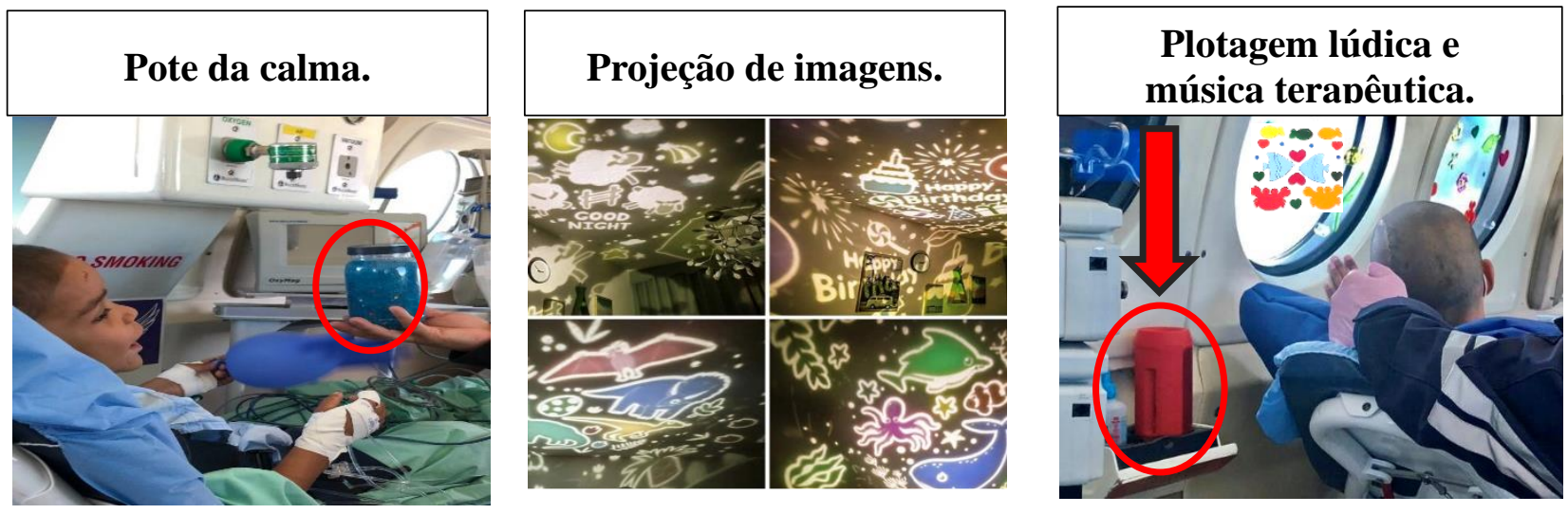


\section{CON \\ CONGRESSO AEROMÉDICO BRASILEIRO}

Os profissionais que trabalham com pacientes críticos vêm explorando diversas modalidades terapêuticas com a intensão de oferecer uma assistência mais humanizada e no transporte aeromédico apesar de não termos encontrado nenhuma literatura de descrevesse a prática acreditamos que os pacientes pediátricos em voos com aviões e helicópteros também podem ser beneficiados com essas terapêuticas, em especial em translados de longa duração.

\section{CONSIDERAÇÕES FINAIS}

A literatura nos mostra que há evidências substanciais para a aplicação como alternativa para minimização de dor e bem-estar de pacientes pediátricos na utilização de terapêuticas complementares e integrativas.

Quando colocamos um paciente em um avião ou helicóptero devemos considerar os estressores a que estes pacientes são submetidos e esse trabalho serviu como base para o entendimento dos benefícios que podem ser alcançados na próxima fase da pesquisa com aplicação prática em voos da Helisul.

\section{REFERÊNCIAS}

ALMEIDA, F.L. A Música na Promoção do Cuidado Humanizado na Unidade de Terapia Intensiva. Dissertação (mestrado) - Universidade Federal da Bahia. Salvador, 2012.

ARAÚJO N.A.; et al. A musicoterapia no tratamento de crianças com autismo: revisão integrativa. Reon Facema [Internet]. 2018. Disponível em: http://www.facema.edu.br/ojs/index.php/ReOnFacema/article/view/349. Acessado: 14 de junho de 2021.

BIRDEE, G.S.; et al. Factors Associated With Pediatric Use of Complementary and Alternative Medicine. Pediatrics [Internet]. 2010 Disponível em: https://pediatrics.aappublications.org/content/125/2/249. Acessado: 14 de junho de 2021.

FARIA, A.C.E. et al.. Método Montessoriano: A importância do ambiente e do lúdico na educação infantil. Revista Eletrônica da Faculdade Metodista Granbery http://re.granbery.edu.br - ISSN 1981 037. Curso de Pedagogia - N. 12, JAN/JUN 2012. Disponível em: http://re.granbery.edu.br/artigos/NDY2.pdf. Acessado: 14 de junho de 2021.

FONTES, C.M.B.; OLIVEIRA, A.S.S.de; TOSO L.A. Brinquedo terapêutico em unidade de terapia intensiva pediátrica. Português/Inglês. Rev enferm UFPE on line., Recife, 11(Supl. 7):2907-15, jul., 2017. DOI: 10.5205/reuol.11007-98133-3SM.1107sup201712 Disponível em: https://periodicos.ufpe.br/revistas/revistaenfermagem/article/download/9518/19201 ISSN: 1981-8963 


\section{CONAER \\ CONGRESSO AEROMÉDICO BRASILEIRO}

$\mathrm{KIM} \mathrm{JH}$, et al. The use of complementary and alternative medicine (CAM) in children: a telephone-based survey in Korea. BMC Complement Altern Med [Internet]. 2012. Disponível em: https://doi.org/10.1186/1472-6882-12-46. Acessado: 14 de junho de 2021.

SILVA, K.M, et al. Música para o coração e a alma na Unidade de Terapia Intensiva. Rev enferm. UFPE, Pernambuco, 2015.

SUEOKA,J.S. FREIXO, J.A.A.; e TAVERNA M. Transporte e Resgate Aeromédico. Guanabara Koogan. Rio de Janeiro, 2021.

VILA, V.da S.C.; ROSSI, L.A. O significado cultural do cuidado humanizado em unidade de terapia intensiva: "muito falado e pouco vivido". Revista Latino Americana. Enfermagem, Ribeirão Preto, v. 10, n. 2, 2002. 